\title{
ANALISIS TINDAKAN KELUARGA DALAM MENANGANI PASIEN ACUTE CORONARY SYNDROME (ACS) PRE HOSPITAL
}

\author{
Novela Lyrizki ${ }^{1}$, Safri $^{2}$, Lita $^{3}$ \\ ${ }^{1,3}$ Program Studi Keperawatan STIKes Hang Tuah Pekanbaru \\ ${ }^{2}$ Fakultas Ilmu Keperawatan Universitas Negeri Riau \\ Email: novelalyrizki18@gmail.com
}

\begin{abstract}
ABSTRAK
Acute coronary syndrome (ACS) merupakan penyakit yang mengancam kehidupan apabila tidak ditangani dengan cepat. Tindakan yang diberikan oleh keluarga kepada pasien ACS dengan tujuan mengurangi keluhan pada pasien yang menyebabkan penundaan untuk datang ke pelayanan kesehatan akan memperburuk keadaan pasien. Penelitian ini dilakukan dengan tujuan untuk mengetahui analisis tindakan keluarga dalam menangani pasien ACS pre hospital di RSUD Arifin Achmad Provinsi Riau. Rancangan penelitian adalah kuantitatif deskriptif dengan jumlah populasi 119 dan sampel 34 orang dengan teknik consecutive sampling. Data dikumpulkan menggunakan kuesioner dan dianalisis secara univariat. Hasil penelitian ini berdasarkan jumlah tindakan didapatkan 14 orang $(41,2 \%)$ yang melakukan satu tindakan, dengan tindakan terbanyak adalah istirahat dan segera dibawa ke rumah sakit. Dengan penelitian ini diharapkan keluarga mampu melakukan tindakan yang tepat dengan mengistirahatkan pasien dan segera membawa pasien ke pelayanan kesehatan dengan segera.
\end{abstract}

Kata kunci: Acute Coronary Syndrome (ACS), Pelayanan kesehatan, Tindakan keluarga

\section{ABSTRACT}

Acute Coronary Syndrome (ACS) is a life-threatening disease if not quickly treated. Actions taken by family of patients with ACS are aimed to minimize complaints which can lead to postponement to come to health services and will aggravate patients' condition. The study was aimed at analyzing actions taken by family to help patients with ACS pre hospital at Arifin Achmad General Hospital of Riau Province A quantitative, descriptive study design was used with the total population of 119, involving 34 samples obtained using consecutive sampling technique. The data were collected using questionnaire and then analyzed using univariate analysis. The study found that based on the number of actions taken, there were 14 respondents (41.2\%) who took only one action, with the most of those actions were resting and taking the patient to the hospital immediately. It is expected that family members are capable of taking appropriate actions by resting and taking the patient immediately to the nearest health service.

Key words: Acute Coronary Syndrome (ACS), Health care, Family action

\section{PENDAHULUAN}

Penyakit jantung iskemik adalah kumpulan sindrom yang disebabkan oleh tidak seimbangnya antara kebutuhan oksigen miokardium dan aliran darah. Penyakit jantung iskemik sering juga disebut penyakit jantung koroner (Kumar, Cotran, \& Robbins, 2013). Diantara penyakit jantung, penyakit jantung koroner ini adalah penyakit jantung utama. Prevalensi penyakit jantung koroner di Indonesia tahun 2013 sebesar $0,5 \%$ atau diperkirakan sekitar 883.447 orang. Di Riau sendiri berdasarkan diagnosis dokter, estimasi jumlah pasien penyakit jantung koroner sebanyak 8.214 orang $(0,2 \%)$ (Riskesdas dalam info datin, 2014).

ACS dibagi menjadi Infark miokard akut dengan elevasi segmen ST (STEMI), infark miokard akut non-elevasi segmen ST (NSTEMI), dan angina pektoris tidak stabil (UAP) (PERKI, 2018). Tanggal 1 Januari - 14 Maret 2019 jumlah pasien ACS yang di rawat inap di RSUD Arifin 
Achmad Provinsi Riau sebanyak 119 orang. Pasien dengan STEMI sebanyak 40 orang, NSTEMI sebanyak 29 orang, dan UAP sebanyak 50 orang (Rekam Medik RSUD Arifin Achmad Pekanbaru, 2019).

Meski penyakit jantung merupakan penyakit yang menjadi pembunuh utama namun masih banyak orang yang melakukan tindakan mandiri untuk mengurangi keluhan pada pasien ACS sehingga terjadi penundaan ke pelayanan kesehatan. Saat serangan merupakan kondisi kedaruratan medis yang sangat berpengaruh terhadap tindakan pertama yang dilakukan saat terjadi serangan. Ada yang mengganggapnya sebagai masuk angin biasa atau karena kelelahan sehingga terjadi penundaan penanganan yang berakibat fatal. Seperti penelitian yang dilakukan oleh Irman, Poeranto, \& Suharsono (2017) di RSUD dr. TC. Hillers Maumere diperoleh sekitar 70\% perilaku pasien ACS yang melakukan penundaan ke rumah sakit. Selama di rumah pasien hanya berbaring, mengobati diri sendiri dan membeli obat di apotek terdekat.

Berdasarkan fenomena di atas maka perlu dilakukan penelitian untuk mengetahui tindakan keluarga pada pasien ACS saat serangan pre hospital, karena mengingat apabila tidak ditangani dengan segera akan berisiko mengakibatkan kondisi yang semakin buruk pada pasien. Tindakan pertolongan pertama yang tepat akan sangat mempengaruhi kondisi pasien dan mengingat risiko yang berpengaruh terhadap kejadian penyakit jantung koroner salah satunya adalah gen, dimana apabila keluarga yang berisiko tidak terpapar tentang penyakit jantung koroner maka akan meningkatkan keparahan bahkan kematian yang diakibatkan oleh penyakit jantung koroner.

\section{METODELOGI PENELITIAN}

Jenis penelitian ini menggunakan rancangan kuantitatif deskriptif. Populasi dalam penelitian ini adalah anggota keluarga yang mendampingi pasien penyakit ACS saat serangan pre hospital yang dirawat di Rumah Sakit Arifin Achmad Provinsi Riau dengan jumlah pasien ACS dari tanggal 1 Januari - 14 Maret 2019 sebanyak 119 orang. Sampel dalam penelitian ini adalah keluarga pasien ACS di ruang CVCU, Krisan, dan IGD yang mengetahui penanganan pasien pre hospital, keluarga yang memiliki anggota keluarga dengan riwayat ACS, keluarga yang dapat berbahasa Indonesia, keluarga yang bersedia menjadi responden. Pengambilan sampel pada penelitian ini menggunakan teknik consecutive sampling dengan alat pengumpulan data menggunakan lembar kuesioner.

\section{HASIL PENELITIAN}

Hasil penelitian yang dilakukan dari bulan mei sampai juli 2019 pada 34 responden anggota keluarga pasien ACS yang dirawat inap di RSUD Arifin Achmad yang memberikan tindakan pada pasien ACS dengan data yang diperoleh sebagai berikut.

\section{A. Karakteristik Responden}

Tabel 1. Distribusi frekuensi usia keluarga pasien Acute Coronary Syndrome (ACS) di Rumah Sakit Umum Daerah Arifin Achmad Provinsi Riau.

\begin{tabular}{ccccc}
\hline Variabel & $\mathrm{n}$ & Mean & $\begin{array}{c}\text { Min- } \\
\text { Max }\end{array}$ & SD \\
\hline Usia & 3 & 47,15 & $20-81$ & 14,955 \\
& 4 & & & \\
\hline
\end{tabular}

Berdasarkan hasil analisis pada tabel 1 dapat disimpulkan bahwa sebagian besar anggota keluarga pasien ACS yang memberikan tindakan pada pasien berusia 
dewasa yaitu mean usia adalah 47,15 tahun.

Tabel 2 Distribusi frekuensi Jenis Kelamin, hubungan keluarga, pendidikan terakhir, pekerjaan dan suku keluarga pasien Acute Coronary

Syndrome (ACS) di RSUD Arifin Achmad Provinsi Riau.

\begin{tabular}{lcc}
\hline \multicolumn{1}{c}{ Karakteristik } & f & $\%$ \\
\hline Jenis kelamin & & \\
a. Laki-laki & 12 & 35,3 \\
b. Perempuan & 22 & 64,7 \\
\hline Hubungan keluarga & & \\
a. Istri & 14 & 41,2 \\
b. Suami & 7 & 20,6 \\
c. Keluarga (anak / & 13 & 38,2 \\
$\quad$ & & \\
\hline
\end{tabular}

Pendidikan terakhir

\begin{tabular}{lcc} 
a. Tidak sekolah & 2 & 5,9 \\
b. SD atau sederajat & 9 & 26,5 \\
c. SMP & 2 & 5,9 \\
d. SMA & 15 & 44,1 \\
e. Perguruan Tinggi & 6 & 17,6 \\
\hline
\end{tabular}

Pekerjaan

\begin{tabular}{|c|c|c|}
\hline a. PNS & 4 & 11,8 \\
\hline b. Wiraswasta & 2 & 5,9 \\
\hline c. Swasta & 6 & 17,6 \\
\hline d. IRT & 18 & 52,9 \\
\hline Petani & 4 & 11,8 \\
\hline
\end{tabular}

Suku

\begin{tabular}{lcc} 
a. Melayu & 15 & 44,1 \\
b. Minang & 9 & 26,5 \\
c. Batak & 2 & 5,9 \\
d. Bugis & 1 & 2,9 \\
e. Banjar & 2 & 5,9 \\
f. Jawa & 4 & 11,8 \\
g. Nias & 1 & 2,9 \\
\hline Total & 34 & 100 \\
\hline
\end{tabular}

Berdasarkan hasil analisis pada tabel 2 dapat disimpulkan bahwa sebagian besar anggota keluarga pasien ACS yang memberikan tindakan pada pasien ACS pre hospital berjenis kelamin perempuan yaitu berjumlah 22 orang $(64,7 \%)$. Mayoritas anggota keluarga pasien ACS yang memberikan tindakan pada pasien ACS pre hospital merupakan istri dari pasien ACS yaitu berjumlah 14 orang (41,2\%). Berdasarkan karakteristik pendidikan terakhir sebagian besar anggota keluarga pasien ACS yang memberikan tindakan pada pasien ACS pre hospital adalah SMA dengan jumlah 15 orang $(44,1 \%)$. Pekerjaan mayoritas anggota keluarga pasien ACS yang memberikan tindakan pada pasien ACS pre hospital adalah IRT dengan jumlah 18 orang $(52,9 \%)$. Sebagian besar anggota keluarga pasien ACS yang memberikan tindakan pada pasien ACS pre hospital bersuku melayu sebanyak 15 orang $(44,1 \%)$.

\section{B. Tindakan keluarga pada pasien ACS pre hospital}

Tabel 2 Distribusi Frekuensi tindakan keluarga pasien Acute Coronary Syndrome (ACS) pre Hospital di Rumah Sakit UmumDaerah Arifin Achmad Provinsi Riau.

\begin{tabular}{|c|c|c|}
\hline Tindakan keluarga & $f$ & $\%$ \\
\hline Istirahat & 15 & 44,1 \\
\hline $\begin{array}{l}\text { Penggunaan } \\
\text { minuman (air putih } \\
\text { hangat) }\end{array}$ & 7 & 20,6 \\
\hline $\begin{array}{l}\text { Pengolesan minyak } \\
\text { kayu putih }\end{array}$ & 7 & 20,6 \\
\hline $\begin{array}{l}\text { Segera di bawa ke } \\
\text { Rumah sakit }\end{array}$ & 7 & 20,6 \\
\hline Pemijatan & 6 & 17,6 \\
\hline $\begin{array}{l}\text { Minum obat jantung } \\
\text { (Aspirin, } \\
\text { Nitrogliserin) }\end{array}$ & 6 & 17,6 \\
\hline $\begin{array}{l}\text { Minum obat } \\
\text { tradisional }\end{array}$ & 5 & 14,7 \\
\hline Kompres air hangat & 4 & 11,8 \\
\hline Faskes pratama & 2 & 5,9 \\
\hline $\begin{array}{l}\text { Pengolesan racikan } \\
\text { tradisional }\end{array}$ & 2 & 5,9 \\
\hline $\begin{array}{l}\text { Penggunaan bawang } \\
\text { putih }\end{array}$ & 1 & 2,9 \\
\hline Minum obat maag & 1 & 2,9 \\
\hline Total & 63 & 100 per \\
\hline
\end{tabular}




$\overline{\text { tindakan }}$

Berdasarkan tabel 2 diketahui bahwa tindakan yang banyak dilakukan oleh keluarga kepada pasien ACS pre hospital adalah istirahat dengan jumlah 15 orang $(44,1 \%)$.

Tabel 3 Distribusi Frekuensi tindakan keluarga berdasarkan jumlah dan jenis tindakan pada pasien ACS pre hospital di RSUD Arifin Achmad Pekanbaru

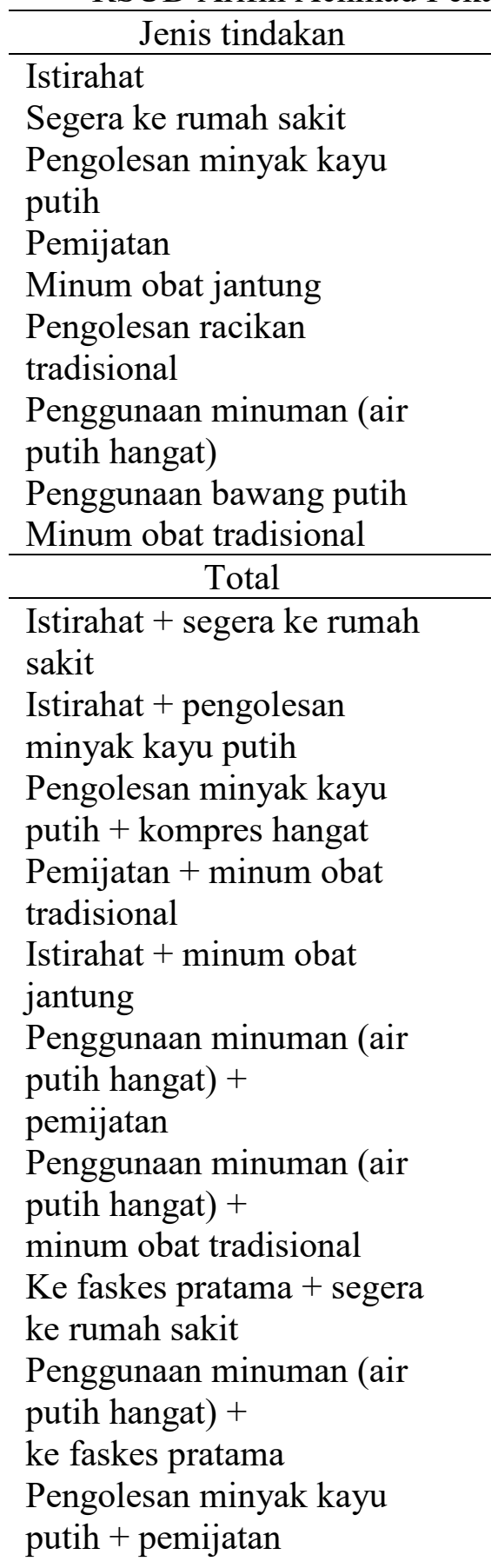

$\begin{array}{ll}3 & 8,8 \\ 3 & 8,8 \\ 2 & 5,9\end{array}$

$1 \quad 2,9$

\begin{tabular}{cc}
14 & 41,2 \\
\hline 2 & 5,9
\end{tabular}

12,9 $\begin{array}{lll}\text { Istirahat }+ \text { minum obat } & 1 & 2,9\end{array}$ tradisional

\begin{tabular}{ccc}
\hline Total & 12 & 35,3 \\
\hline Istirahat + minum obat & 2 &
\end{tabular}

jantung +

kompres hangat

Minum obat jantung $+\quad 1$

kompres +

pengolesan minyak kayu

putih

Istirahat + penggunaan $\quad 1$

minuman (air putih hangat) +

pemijatan

Istirahat + pemijatan +

minum obat maag

Penggunaan minuman (air

$1 \quad 2,9 \quad$ putih hangat) +

12,9 pengolesan minyak kayu

12,9 putih + minum obat

tradisional

$1 \quad 2,9 \quad$ istirahat + pengolesan

racikan tradisional +

$1 \quad 2,9 \quad$ segera ke rumah sakit

Istirahat + minum obat

jantung +

penggunaan minuman (air

putih hangat) +

kompres hangat

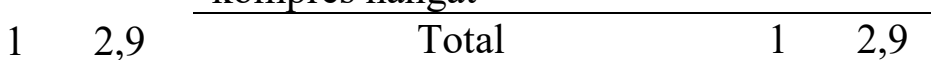

12,9 Berdasarkan tabel 3 didapatkan bahwa, tindakan keluarga pasien ACS

12,9 berdasarkan jumlah dan jenis tindakan yang dilakukan pre hospital terbanyak adalah istirahat dan segera ke rumah sakit sebanyak 3 orang.

$1 \quad 2,9 \quad$ PEMBAHASAN

\section{A. Karakteristik responden}

\section{Usia}

$1 \quad 2,9 \quad$ Berdasarkan penelitian yang dilakukan di RSUD Arifin Achmad didapatkan bahwa

12,9 dari 34 anggota keluarga pasien Acute Coronary Syndrome (ACS) dengan mean usia 47,15 tahun. Penelitian ini menggambarkan tindakan kepada keluarga pada pasien ACS lebih banyak 
dilakukan oleh usia dewasa dikaitkan dengan usia pasien ACS yang mayoritas berada di usia dewasa hingga lansia, sehingga pasien yang sudah menikah akan didampingi oleh pasangan dengan usia yang hampir sama. Potter dan Perry (2010) menjelaskan bahwa, Middle age atau usia pertengahan adalah usia yang berkisar antara 30-an menengah sampai usia pertengahan 60 -an. Usia pertengahan ini merupakan suatu masa dimana pokok permasalahan sudah dipikirkan dengan mantap karena di usia middle age sudah memiliki pengalaman yang banyak sehingga keputusan sudah bisa diambil, salah satunya keputusan untuk mengambil keputusan memberikan tindakan kepada keluarga yang sakit.

Sejalan dengan penelitian yang dilakukan oleh Saberi, Mohsen, dan Javad (2014) menyebutkan bahwa mayoritas usia yang mengakses pelayanan kesehatan pada pasien infark miokard akut adalah 40-56 tahun. Hal ini kemungkinan dikaitkan dengan kejadian ACS yang paling banyak menyerang usia yang lebih tua, namun tidak menutup kemungkinan pasien yang lebih muda juga dapat terkena serangan ACS. Secara umum, pasien sampai atau datang ke pelayanan kesehatan dengan didampingi oleh wali dan biasanya berusia dewasa.

\section{Jenis kelamin}

Hasil penelitian yang dilakukan di RSUD Arifin Achmad Provinsi Riau didapatkan bahwa dari 34 anggota keluarga pasien ACS yang memberikan tindakan pada pasien saat serangan pre Hospital lebih banyak berjenis kelamin perempuan yaitu sebanyak 22 orang $(64,7 \%)$. Penelitian ini menggambarkan tindakan keluarga pada pasien ACS lebih banyak dilakukan oleh perempuan dikaitkan dengan pasien ACS yang didomisili oleh laki-laki. Selain itu, berdasarkan wawancara dengan anggota keluarga yang memberikan tindakan pre hospital pada pasien ACS adalah anak perempuannya.
Sejalan dengan penelitian yang dilakukan oleh Ubaydillah (2017) bahwa, anggota keluarga pasien ACS yang mengakses pelayanan kesehatan lebih banyak berjenis kelamin perempuan. Berkaitan dengan peran perempuan yang sangat penting dalam sebuah keluarga, mayoritas dalam sebuah keluarga perempuan lebih cenderung sebagai seseorang yang mampu merawat anggota keluarga terutama dalam keadaan sakit, sehingga pengambilan keputusan lebih dipusatkan pada perempuan. Berdasarkan hasil wawancara yang dilakukan oleh peneliti, perempuan berada disisi pasien selama 24 jam, baik yang diruang rawat jantung Krisan, maupun CVCU dan cenderung tidak mau untuk digantikan selama menunggu pasien yang rata-rata adalah pasangannya, dengan alasan takut akan terjadi hal yang tidak diinginkan ketika pasien tidak dijaga olehnya.

\section{Hubungan keluarga}

Hasil penelitian yang dilakukan di RSUD Arifin Achmad Provinsi Riau didapatkan bahwa dari 34 anggota keluarga pasien ACS yang memberikan tindakan pada pasien saat serangan pre Hospital lebih banyak adalah statusnya istri dari pasien. Penelitian ini menggambarkan tindakan keluarga pada pasien ACS lebih banyak dilakukan oleh perempuan dikaitkan dengan laki-laki lebih sering terkena penyakit jantung koroner dibandingkan perempuan (Kumar, Cotran, \& Robbins, 2013). Sehingga pasien yang sudah menikah akan didampingi oleh istrinya. Sejalan dengan penelitian yang dilakukan oleh Gard dan Kring (2007) menjelaskan bahwa perempuan lebih banyak menuju ke pelayanan kesehatan dikarenakan perempuan lebih mengedepankan emosional. Perempuan juga dinilai sebagai makhluk yang sabar, terutama dalam urusan merawat anggota keluarga yang sedang sakit.

\section{Pendidikan}


Pendidikan menurut UU RI No.20 tentang sistem pendidikan Nasional tahun 2003 merupakan usaha sadar dan terencana untuk mewujudkan suasana belajar dan proses pembelajaran agar peserta didik secara aktif mengembangkan potensi dirinya untuk memiliki kekuatan spiritual, keagamaan, pengendalian diri, kepribadian, kecerdasan, akhlak mulia, serta keterampilan yang diperlukan dirinya, masyarakat, bangsa dan negara. Pendidikan dikategorikan menjadi tiga, pertama pendidikan rendah yaitu SD dan SMP, kedua pendidikan menengah yaitu SMA, dan ketiga pendidikan tinggi yaitu perguruan tinggi.

Berdasarkan hasil penelitian pada karakteristik pendidikan terakhir, hasil analisis menunjukkan bahwa sebagian besar pendidikan terakhir responden adalah SMA yang berarti sebagian besar responden masuk kedalam kategori pendidikan menengah. Sejalan dengan penelitian yang dilakukan oleh Rahmawati, Rosjidi, \& Nurhidayat (2018) menyebutkan bahwa pasien atau keluarga yang memiliki tingkat pendidikan menengah yaitu SMA memiliki tingkat keterlambatan pra-rumah sakit yang lebih rendah.

Dapat diambil kesimpulan bahwa pendidikan berkontribusi pada modal manusia dengan mengembangkan berbagai ketrampilan dan sifat, seperti kemampuan kognitif, kemampuan memecahkan masalah, keefektifan belajar, dan kontrol pribadi. Akibatnya, pendidikan akan mempengaruhi kesehatan dengan cara yang bervariasi. Penelitian ini menggambarkan, individu dengan jenjang pendidikan menengah sudah termasuk memiliki tindakan yang benar pada pasien ACS.

\section{Pekerjaan}

Berdasarkan penelitian yang dilakukan di RSUD Arifin Achmad Provinsi Riau didapatkan bahwa dari 34 responden yang melakukan tindakan pada pasien ACS lebih banyak IRT, yaitu 18 orang $(52,9 \%)$. Penelitian ini menggambarkan tindakan kepada keluarga pada pasien ACS lebih banyak dilakukan oleh perempuan berstatus sebagai IRT dikaitkan dengan pasien ACS yang didomisili oleh laki-laki. Hasil penelitian ini didukung oleh penelitian yang dilakukan Putri (2018) menyatakan bahwa mayoritas yang memanfaatkan pelayanan kesehatan yaitu IRT yang berstatus tidak bekerja, dikarenakan ibu rumah tangga dinilai memiliki banyak waktu luang sehingga dapat setiap saat menuju pelayanan kesehatan dan tidak terkendala waktu. Asumsi peneliti IRT lebih banyak memiliki kesempatan untuk memperhatikan kondisi anggota keluarga lain saat dalam kondisi sakit, sehingga lebih memungkinkan untuk memberikan pertolongan pertama.

\section{Suku}

Berdasarkan penelitian yang dilakukan di RSUD Arifin Achmad Provinsi Riau didapatkan bahwa dari 34 responden yang melakukan tindakan pada pasien ACS lebih banyak bersuku melayu, yaitu 15 orang $(44,1 \%)$. Di dukung oleh data Survei Konsumsi Makanan Indonesia (SKMI) tahun 2014 menunjukkan bahwa proporsi penduduk Indonesia yang mengkonsumsi lemak lebih dari 67 gram perhari sebesar 26,5\%. Data dari Kantor Walikota Pekanbaru (2015) menyebutkan bahwa etnis yang memiliki proporsi cukup besar di Pekanbaru kedua adalah suku Melayu. Suku melayu memiliki makanan khas dan makanan tradisional yang juga biasanya dikonsumsi sehari-hari dan dalam jangka panjang oleh masyarakatnya yaitu gulai ikan salai, roti jala santan, tumis belacan yang menggunakan santan (Kemdikbud, 2017). Berdasarkan wawancara yang dilakukan kepada anggota keluarga pasien ACS, keluarga menggemari makanan bersantan dan dikonsumsi turun temurun. 
Hasil penelitian yang dilakukan oleh Malonda, Dinarti, \& Pangastuti (2012), menunjukkan bahwa adanya hubungan antara asupan lemak dengan terjadinya hipertensi. Konsumsi makanan yang tinggi lemak dapat menyebabkan aterosklerosis atau penyempitan pembuluh darah. Akibatnya pembuluh darah menjadi kaku dan elastisitasnya berkurang yang akan meningkatkan resiko terjadinya ACS. Asumsi peneliti makanan yang dikonsumsi sehari-hari dalam jangka panjang akan mempengaruhi kesehatan.

Dpat diambil kesimpulan bahwa suku Melayu yang merupakan etnis terbesar kedua di Riau sehingga memungkinkan keluarga pasien ACS terbanyak bersuku Melayu, kemudian berkaitan dengan makan yang dikonsumsi suku Melayu merupakan makanan yang mengandung santan dan dikonsumsi dalam jangka panjang yang semakin meningkatkan risiko terjadinya aterosklerosis.

\section{B. Tindakan keluarga pada pasien ACS pre hospital}

Berdasarkan penelitian yang dilakukan di RSUD Arifin Achmad Provinsi Riau didapatkan bahwa dari 34 responden yang melakukan tindakan terbanyak pada pasien ACS adalah dengan beristirahat, kemudian penggunaan minuman (air putih hangat), pengolesan minyak kayu putih, segera dibawa ke rumah sakit, minum obat jantung (aspirin, Nitrogliserin), pemijatan, minum obat tradisional, kompres air hangat, pengolesan racikan tradisional, ke faskes pratama, dan penggunaan bawang putih.

Kurang dari 6 jam merupakan golden periode pada ACS. Maka dari itu pasien ketika serangan harus segera dalam keadaan istirahat untuk mengurangi kerja jantung dan segera bawa ke pelayanan kesehatan untuk ditetapkannya diagnosis apakah pasien ACS dengan STEMI, NSTEMI, ataupun UAP. Fokus awal IGD berada pada identifikasi pasien dengan STEMI, dilakukan EKG dan dibaca dalam
10 menit setelah pasien datang (Black \& Hawks, 2014).

Hasil penelitian yang dilakukan di RSUD Arifin Achmad Provinsi Riau didapatkan yang melakukan 1 tindakan pada pasien ACS yang terbanyak. Diantaranya 3 orang memberikan tindakan mengistirahatkan pasien, 3 orang segera membawa pasien ke rumah sakit, 2 orang memberikan tindakan pengolesan minyak kayu putih, 1 orang memberikan tindakan pijat, 1 orang memberikan obat jantung, 1 orang melakukan tindakan pengolesan racikan tradisional, 1 orang penggunaan minuman (air putih hangat), 1 orang memberikan tindakan penggunaan bawang putih, dan 1 orang penggunaan obat tradisional. Seluruh responden merupakan keluarga pasien rawat inap yang menggunakan fasilitas kesehatan di RSUD Arifin Achmad. Tindakan yang dilakukan oleh keluarga sudah benar dengan membawa pasien ACS ke Rumah Sakit untuk diberikan tindakan yang tepat untuk tujuan mempertahankan fungsi jantung.

\section{Istirahat}

Pertolongan pertama saat terjadi serangan jantung dengan beristirahat merupakan tindakan yang paling tepat. Setelah pasien sudah relaks, hal yang harus dilakukan selanjutnya adalah meminta bantuan orang lain segera menelepon ambulan. Menghentikan segala aktivitas, tidak melakukan banyak gerakan dan segera meminta bantuan merupakan langkah yang tepat untuk mengatasi di area pra rumah sakit (Harwono, 2013).

Kondisi relaks yang dihasilkan melalui proses relaksasi dapat memberikan pengaruh terhadap skala nyeri didasarkan pada teori Gate Control yang menjelaskan bahwa nyeri yang terjadi pada seseorang akibat adanya rangsangan tertentu dapat diblok ketika terjadi interaksi antara stimulus nyeri dan stimulus pada serabut yang mengirimkan sensasi tidak nyeri diblok pada sirkuit gerbang penghambat. Pemblokan ini dapat dilakukan melalui 
pengalihan perhatian ataupun dengan tindakan relaksasi (Sugiarto, Anies, Julianti, \& Mardiyono, 2015). Kesimpulan yang dapat diambil adalah ketika pasien serangan segera menghentikan segala aktifitas dan istirahat akan mengurangi beban kerja jantung dalam memenuhi kebutuhan oksigen tubuh. Dan sesegera mungkin pasien dibawa ke pelayanan kesehatan karena harus dilakukan penilaian rekaman EKG 12 sadapan.

\section{Minum air putih hangat}

Hasil penelitian yang dilakukan di RSUD Arifin Achmad didapatkan bahwa dengan minum air putih hangat pasien mengatakan nyeri sedikit berkurang. Minum air putih hangat memberikan efek hidrostatik dan hidrodinamik dan hangatnya membuat sirkulasi peredaran darah khususnya pada daerah paru-paru agar menjadi lancar. Secara fisiologis, air hangat juga memberi pengaruh oksigenisasi dalam jaringan tubuh (Hamidin, 2012). Kesimpulan yang dapat diambil adalah ketika pasien serangan dengan dilakukannya tindakan pemberian air putih hangat akan membuat pasien lebih relaks dan juga memberi pengaruh oksigenisasi dalam jaringan tubuh yang dapat mengurangi nyeri yang dirasakan pasien.

\section{Pengolesan minyak kayu putih}

Hasil penelitian yang dilakukan di RSUD Arifin Achmad Pekanbaru sebanyak 7 responden yang memberikan minyak kayu putih. Minyak kayu putih merupakan salah satu minyak atsiri yang diperoleh dari hasil penyulingan daun kayu putih. Minyak kayu putih memiliki khasiat utama yaitu untuk melancarkan peredaran darah dengan melebarkan pori-pori kulit sehingga badan menjadi lebih hangat dan tidak akan mengganggu pernafasan kulit karena adanya sifat dari minyak kayu putih yang sudah menguap (Agoes, 2010). Peneliti berasumsi bahwa dengan badan menjadi hangat oleh minyak kayu putih badan akan menjadi lebih relaks yang akan mengurangi kerja jantung dalam memenuhi kebutuhan oksigen tubuh.

\section{Segera dibawa ke rumah sakit}

Tujuan tindakan dipercepat di IGD rumah sakit agar tindakan reperfusi dilakukan hasilnya akan lebih baik. Mencegah terjadinya infark miokard atau membatasi luasnya infark dan mempertahankan fungsi jantung. Terapi yang diberikan kepada pasien dengan diagnosis kemungkinan ACS atas dasar keluhan angina di IGD, sebelum ada hasil EKG dan marka jantung (PERKI, 2015).

Pasien tirah baring atau posisi ternyaman pasien untuk menurunkan kerja jantung, suplemen oksigen harus diberikan segera untuk pasien dengan saturasi $\mathrm{O} 2$ arteri < $95 \%$ atau yang mengalami distres respirasi, suplemen oksigen dapat diberikan pada semua pasien ACS dalam 6 jam pertama, tanpa mempertimbangkan saturasi $\mathrm{O} 2$ arteri, aspirin 160-320 mg diberikan segera pada semua pasien yang tidak diketahui intoleransinya terhadap aspirin, aspirin tidak bersalut lebih terpilih mengingat absorbsi sublingual yang lebih cepat, penghambat reseptor ADP (adenosine diphosphate) dosis awal ticagrelor yang dianjurkan adalah $180 \mathrm{mg}$ dilanjutkan dengan dosis pemeliharaan $2 \mathrm{x}$ $90 \mathrm{mg} /$ hari kecuali pada pasien STEMI yang direncanakan untuk reperfusi menggunakan agen fibrinolitik (PERKI, 2015)

Kemudian diberikan Nitrogliserin spray/tablet sublingual bagi pasien dengan nyeri dada yang masih berlangsung saat tiba di ruang gawat darurat. Apabila nyeri dada yang dirasakann pasien tidak hilang dengan satu kali pemberian, dapat diulang lagi setiap lima menit sampai maksimal tiga kali pemberian. Nitrogliserin intravena diberikan pada pasien yang tidak responsif dengan terapi tiga dosis NTG sublingual dalam keadaan tidak tersedia NTG, Isosorbid dinitrat (ISDN) dapat dipakai sebagai pengganti, morfin sulfat 1-5 mg intravena, dapat diulang 
setiap 10-30 menit, bagi pasien yang tidak responsif dengan terapi tiga dosis NTG sublingual (PERKI, 2015). Peneliti berasumsi bahwa pasien ACS ketika serangan harus segera menghentikan segera aktifitas dan sesegera mungkin dibawa ke pelayanan kesehatan untuk dilakukan segera tindakan yang tepat untuk menurunkan resiko terjadinya infark miokard ataupun membatasi luasnya infark miokard dan mempertahankan fungsi jantung.

\section{Minum obat jantung}

Aspirin merupakan salah satu tata laksana dasar pada pasien yang dicurigai STEMI. Inhibisi cepat siklooksigenase trombosit yang dilanjutkan dengan reduksi kadar tromboksan A2 dicapai dengan absorbsi aspirin bukal dengan dosis $162 \mathrm{mg}-325$ $\mathrm{mg}$ di ruang emergensi dengan daily dose 75 - 162 mg (Darliana, 2010). Aspirin merupakan antiplatelet yang efektif sebagai pencegahan primer dan skunder pada kejadian aterotrombotik (Yunita, Zulkarnain. Aminuddin, 2015). Dan nitrogliserin (NTG) sublingual dapat diberikan dengan dosis $0,4 \mathrm{mg}$ dan dapat diberikan sampai 3 dosis dengan interval 5 menit. NGT berfungsi untuk mengurangi nyeri dada juga untuk menurunkan kebutuhan oksigen miokard dengan menurunkan preload dan meningkatkan suplai oksigen miokard dengan cara dilatasi pembuluh darah koroner yang terkena infark atau pembuluh kolateral. NTG harus dihindari pada pasien dengan tekanan darah sistolik $<90 \mathrm{mmHg}$ atau pasien yang dicurigai mengalami infark ventrikel kanan (Darliana, 2010). Kesimpulan yang dapat diambil adalah aspirin yang efektif mencegah terbentuknya trombus di pembuluh darah. Dan NTG yang berfungsi untuk mengurangi nyeri dada juga menurunkan kebutuhan oksigen miokard dengan cara dilatasi pembulu darah koroner.

\section{Pemijatan}

Pemijatan mempengaruhi aktifitas saraf autonom, mempersepsikan relaksasi serta dalam Trisnowiyanto (2012) menjelaskan massage atau pijat dapat melancarkan peredaran darah terutama pada peredaran darah. Tindakan pijat merupakan salah satu upaya untuk relaksasi yang mengaktifkan thalamus untuk mengeluarkan hormone endorphin enkafalin yang dapat mengatasi nyeri (Hariyanto, Hadisaputra, \& Supriyadi, 2015). Peneliti berasumsi bahwa dengan dilakukan pemijatan akan mengurangi nyeri karena pasien akan merasakan keadaan relaks yang akan mengurangi beban kerja jantung dalam memenuhi kebutuhan oksigen tubuh.

\section{Minum obat tradisional}

Hasil penelitian yang dilakukan di RSUD Arifin Achmad sebanyak 5 responden memberikan tindakan dengan pemberian obat tradisional. Obat tradisional yang digunakan disini adalah habbaratus saudah yang memiliki aktivasi sebagai anti inflamasi, analgetik, dan antipiretik (Radji, 2011). Kesimpulan yang dapat diambil adalah dengan pemberian habbaratus saudah yang berfungsi sebagai analgetik dapat mengurangi nyeri. Namun pasien harus tetap dibawa ke rumah sakit untuk dilakukan penanganan yang lebih tepat untuk mempertahankan fungsi jantung pada pasien ACS.

\section{Kompres air hangat}

Memberikan kompres hangat di bagian dada pada pasien ACS akan membuat pasien lebih relaks dan tenang yang akan mengurangi kerja jantung dalam memenuhi oksigen. Pemberian kompres hangat terhadap pengobatan nyeri yaitu membuat otot-otot yang tegang menjadi rileks sehingga nyeri menjadi berkurang (Fauziyah, 2013). Efek fisiologis kompres hangat bersifat vasodilatasi yaitu meredakan nyeri dengan merelaksasi otot, meningkatkan aliran darah, memiliki efek sedatif dan meredakan nyeri dengan menyingkirkan produk-produk inflamasi 
yang menimbulkan nyeri (Felina, Masrul, \& Iryani, 2015). Kompres hangat bekerja dengan cara induksi, yaitu terjadinya perpindahan panas dari kompres ke dalam daerah yang terasa nyeri, panas bekerja dengan cara menstimulasi reseptor nyeri untuk memblok reseptor nyeri (Pratintya, Harmilah \& subroto, 2014). Panas juga meningkatkan pengiriman nutrisi dan kebutuhan oksigen ke daerah yang diberikan kompres serta kongesti vena menurun, meningkatkan suplai darah ke area-area tubuh. Kompres air hangat dapat membuat sirkulasi darah lancar dan vaskularisasi lancar yang membuat relaksasi pada otot, dan kekakuan sendi (Murtiningsih \& Karlina, 2015). Kesimpulan yang dapat diambil adalah kompres hangat dapat mengurangi nyeri yang dirasakan pasien ACS karena dengan kompres hangat pasien akan menjadi lebih relaks yang akan mengurangi kerja jantung.

\section{Pengolesan racikan tradisional}

Pengolesan racikan tradisional ini merupakan tindakan yang dipercaya responden dan pasien untuk mengurangi nyeri. Dengan memberikan tindakan pengolesan racikan tradisional akan membuat pasien lebih relaks yang akan mengurangi kerja jantung. Ketika terjadinya serangan dan keluarga yang memberikan tindakan dapat membuat pasien relaks akan mengurangi kerja jantung. Dengan berkurangnya beban jantung, maka kebutuhan dan suplai akan seimbang. Namun pasien harus tetap dibawa ke rumah sakit untuk dilakukan penanganan yang lebih tepat untuk mempertahankan fungsi jantung pada pasien ACS.

\section{Faskes pratama}

Hasil penelitian yang dilakukan di RSUD Arifin Achmad Pekanbaru ada beberapa pasien yang datang ke bidan desa. Bidan desa merupakan salah satu fasilitas kesehatan pratama. Hasil wawancara kepada responden menyebutkan pasien hanya diberikan $\mathrm{O} 2$ dan obat anti nyeri kemudian diperbolehkan pulang. Sedangkan Permenkes nomor 71 tahun 2013 mengenai pelayanan kebidanan Pasal 16 dan 18 menyebutkan bahwa pelayanan kesehatan tingkat pertama diantaranya mencakup pemeriksaan ibu hamil, nifas, ibu menyusui, bayi dan anak balita atau dokter, pertolongan pervaginam bukan risiko tinggi, pertolongan persalinan dengan komplikasi dan/ atau penyulit pervaginam, dan pertolongan neonatal dengan komplikasi.

Hal ini dapat menyebabkan keterlambatan penanganan pada pasien ACS. Ketika terjadi serangan jantung maka fungsi pompa jantung akan menurun karena ketidakseimbangan antara kebutuhan miokardium dan suplai sehingga aliran darah ke otak berkurang yang akan mengakibatkan penurunan kesadaran. Namun tindakan akhir keluarga pada pasien ACS tetap benar dengan membawa pasien ke rumah sakit untuk menurunkan resiko terjadinya infark miokard ataupun membatasi luasnya infark miokard dan mempertahankan fungsi jantung.

\section{Minum obat maag}

Hasil penelitian yang dilakukan di RSUD Arifin Achmad satu responden minum obat maag saat terjadi serangan. Persepsi yang salah terhadap penyakit ACS, pasien ACS merasakan keluhan yang dialaminya adalah nyeri di bagian belakang tubuh yang menganggap nyeri disebabkan oleh penyakit maag (Pohan, 2007). Hasil wawancara kepada responden menyebutkan membeli obat maag di warung karena sudah biasa apabila merasakan keluhan responden membeli obat di warung saja. Didukung oleh penelitian yang dilakukan oleh Irman, Poeranto, \& Suharsono (2017) di RSUD dr. TC. Hillers Maumere diperoleh sekitar $70 \%$ perilaku pasien ACS yang melakukan penundaan ke rumah sakit dan selama di rumah pasien hanya berbaring, 
dan mengobati diri sendiri dan membeli obat di apotek terdekat.

Hasil penelitian yang sama juga ditunjukkan oleh Mussi et al (2014) dimana hanya $23,7 \%$ pasien yang menginterpretasikan gejala sebagai serangan jantung, dan sisanya mempersepsikan bahwa gejala diakibatkan oleh penyebab lain seperti masalah pencernaan, kelelahan dan masuk angin. Kesimpulan yang dapat diambil adalah responden yang mempersepsikan bahwa gejala tersebut diakibatkan oleh penyakit lain yang bukan serangan jantung dikawatirkan akan dilakukan penundaan ke pelayanan kesehatan. Sedangkan yang terjadi pada pasien ACS merupakan defisit kritis dalam suplai darah pada jantung yang berbanding dengan kebutuhan oksigen dan nutrien, atau terjadinya ketidakseimbangan antara kebutuhan dan suplai yang menyebabkan perkembangan sindrom koroner akut (Black \& Hawks, 2014). Namun tindakan akhir keluarga pada pasien ACS tetap benar dengan membawa pasien ke rumah sakit untuk menurunkan resiko terjadinya infark miokard ataupun membatasi luasnya infark miokard dan mempertahankan fungsi jantung.

\section{Penggunaan bawang putih}

Hasil penelitian yang dilakukan di RSUD Arifin Achmad satu responden menggunakan bawang putih yang dikonsumsi ketika serangan. Bawang putih dapat mengurangi pembekuan darah dan mengurangi tekanan darah. Allisin dan adrenosin merupakan kandungan antiplatelet paling penting dalam bawang putih. Minyak bawang putih yang diberikan kepada pasien penyakit jantung koroner dapat menghambat agregasi platelet secara in vivo. Pemberian bawang putih dengan dosis rendah menghambat agregasi platelet tersebut. Dithlin dan ajoene menurunkan kecepatan pembekuan darah karena bersifat antikoagulasi dan darah rendah. Umbi bawang putih merupakan sebagai agen anti-agregasi platelet (Hernawan \& Setyawan, 2003). Kesimpulan yang dapat diambil adalah dengan bawang putih dapat mencegah trombus, namun tidak disebutkan dengan jelas pada jurnal berapa dosis yang digunakan.

Berdasarkan penjabaran diatas tindakan keluarga dengan istirahat merupakan tindakan yang paling tepat untuk tujuan meringankan beban jantung pada pasien ACS. Ketika melakukan aktivitas maka kerja jantung akan semakin meningkat yang membuat jantung semakin kekurangan suplai. Dengan melakukan macam-macam tindakan pre Hospital seperti yang telah dijabarkan diantaranya minum air putih hangat, pengolesan minyak kayu putih, pemijatan area nyeri, minum obat tradisional, kompres air hangat, pengolesan racikan tradisional yang hanya akan membuat nyeri berkurang. Namun tindakan segera ke rumah sakit setelah pasien diistirahatkan kurang dari 6 jam merupakan hal yang sangat penting untuk mempertahankan fungsi jantung. Tindakan keluarga yang membawa pasien ACS ke bidan desa merupakan tindakan yang kurang tepat.

\section{KESIMPULAN}

Berdasarkan penelitian yang dilakukan oleh peneliti di RSUD Arifin Achmad Provinsi Riau mengenai analisis tindakan keluarga pada pasien ACS pre hospital dapat diambil kesimpulan bahwa rata-rata usia responden adalah 37,15 tahun, berjenis kelamin perempuan, hubungan keluarga adalah istri, tingkat pendidikan menengah (Sekolah Menengah Atas), berstatus IRT, bersuku melayu. Tindakan keluarga pasien ACS pre Hospital berdasarkan jumlah tindakan yang terbanyak adalah istirahat dan ada pula keluarga yang segera membawa pasien ACS ke Rumah sakit.

\section{SARAN}


1. Bagi STIKes Hang Tuah Pekanbaru

Peneliti mengharapkan agar dapat menambahkan materi pembelajaran, terutama yang berkaitan dengan penyakitpenyakit yang bergantung pada waktu seperti Acute Coronary Syndrome (ACS) ke dalam proses pembelajaran, agar nantinya dapat diterapkan mahasiswa kepada siapapun dan dimanapun, termasuk dirinya sendiri.

2. Bagi Rumah Sakit Umum Daerah Arifin Achmad Provinsi Riau

Peneliti mengharapkan agar pihak rumah sakit meningkatkan edukasi mengenai ACS dan waktu ideal penanganannya pada masyarakat, pasien, dan keluarga untuk meningkatkan kewaspadaan dan mencegah keparahan penyakit ketika terjadi serangan berulang.

3. Bagi ilmu keperawatan

Peneliti mengharapkan agar mahasiswa keperawatan yang akan melakukan pendidikan profesi untuk lebih mendalami ilmunya yang berkaitan dengan ACS untuk dapat diterapkan pada saat praktik dan digunakan dalam dunia kerja.

4. Bagi peneliti selanjutnya

Peneliti mengharapkan agar penelitian ini dapat digunakan sebagai referensi untuk meneliti lebih dalam tentang waktu yang digunakan dan transportasi yang digunakan untuk menuju ke pelayanan kesehatan.

\section{DAFTAR PUSTAKA}

Agoes, A. (2010). Tanaman obat Indonesia. Jakarta: Salemba Medika.

Black, J.M \& Hawks, J.H. (2014). Keperawatan medikal bedah. Singapore: Elsevier.

Darliana, D. (2010). Manajemen pasien ST elevasi miokardial infark (STEMI). Idea nursing journal ISSN: 2087-2879.

Fauziyah, I. Z. (2013). Efektifitas teknikeffleurage dan kompres hangat terhadap penurunan tingkat disminore. Jurnal Universitas Gresik, Vol. 1 No. 1. Gresik: Universitas Gresik.
Felina, M., Masrul., \& Iryani, D. (2015). Pengaruh kompres panas dan dingin terhadap penurunan nyeri kala I fase aktif persalinan fisiologis ibu primipara. Jurnal kesehatan Andalas, Vol.4 No. 1. Padang: Universitas Andalas.

Hamidin, A. S. (2012). Keampuhan terapi air putih. Jakarta: PT Buku Seru.

Harnowo, P. A. (2013). P3K: Pertolongan pertama dan Penanganan Darurat. Retrieved from www.itokindo.org.

Hernawan, U. E., Setyawan, A.D. (2003). Senyawa organosurfur bawang putih. Biofarmasi Journal. Vol 1, No. 2, Agustus 2003, hal 65 - 76.

Majid, A. (2008). Penyakit jantung koroner: patofisiologi, pencegahan, dan pengobatan terkini. Universitas Sumatera Utara (USU). http://repository.usu.ac.id/bitstream/ha ndle/123456789/705/08E00124.pdf;jse ssionid=A2220FE54116106DD317219 681227D52? sequence $=1$

Malonda, N. S. H., Dinarti, L. K., \& Pangastuti, R. (2012). Pola makan dan konsumsi alkohol sebagai faktor risiko hipertensi pada lansia. Jurnal gizi klinik Indonesia Vol.8, No.4: 202-212.

Murtiningsih., \& Karlina, L. (2015). Penurunan nyeri disminore primer melalui kompres hangat pada remaja. Jurnal STIKES Agmad Yani, Vol. 3, No.2. Cimahi: STIKES Ahmad Yani.

PERKI. (2018). Pedoman tata laksana Sindrom Koroner Akut. www.inaheart.org.

Pohan, H. T. (Mei, 2007). Masuk angin bisa berujung maut. Humas Universitas Indonesia Kliping, 3 4.

Pratintya, A. D., Harmilah., \& Subroto. (2014). Kompres hangat menurunkan nyeri persendian osteoartritis pada lanjut usia. Jurnal kebidanan dan keperawatan, Vol.10, No. 1. Yogyakarta: Poltekkes Kemenkes. 
Putri, E.D., (2018). Hubungan illness perception dengan health seeking behavior pasien acute coronary syndrome (ACS) di Rumah sakit umum daerah Arifin Achmad Provinsi Riau. Stikes HangTuah Pekanbaru.

Radji, M. (2011). Mikrobiologi Buku Kedokteran. Jakarta:EGC.

Sugiarto, A., Anies., Julianti, H.P., \& Mardiono. (2015). Intervention baased on nursing integration with islam relaxation to decrease anxiaty and pain on IMA patients in ICU. Journal kesehatan Vol.11. ISSN 1829-5754.

Trisnowiyanto, B. (2012). Keterampilan dasar massage. Jogyakarta: Nuha Medika.

Ubaydillah, R. (2017). Faktor-faktor yang berhubungan dedngan Health seeking behavior pasien acute coronary syndrome (ACS) di Rumah sakit umum daerah Arifin Achmad Provinsi Riau. Stikes HangTuah Pekanbaru. Skripsi tidak dipublikasi. 